\section{A systematic review: the role of spirituality in reducing depression in people living with HIV/AIDS}

Vermandere et al's' article highlighted endof-life care as a particular area where spirituality can play an important role. In a link between spirituality and another chronic disease we looked at spirituality and HIV (R Amuzie, unpublished data, 2009). Vermandere's literature review proposes that spirituality has a key position in the management of HIV sufferers. HIV infection is a major global problem and in 2007 was present in 33 million people around the world. ${ }^{2}$ Antiretroviral therapy has been successful in slowing the progression of HIV infection and reducing AIDS-related mortality. But by doing so, HIV infection is now widely considered as a chronic illness and therefore HIV sufferers are beleaguered by similar challenges as those living with chronic illnesses like epilepsy and diabetes mellitus. Research suggests that people with HIV/AIDS are at greater risk of depression, ${ }^{3}$ and that depression in HIV sufferers is linked with more rapid loss of immune function, accelerated disease progression, and lower survival time. ${ }^{4}$

In clinical research, spirituality has been broadly defined as a belief in a higher power than oneself that is not thought to be God. Another definition is that spirituality is similar to an individuals' experience of meaning and life purpose. ${ }^{5}$ It has been reported to reduce the risk of depression in people living with chronic illness. This review was conducted to examine the possible benefits and impact of spirituality on depressive symptoms in people with HIV/AIDS.

Systematic literature searches of PubMed, Psyclnfo, and Embase were carried out, along with backwards and forwards citation tracking of key studies, identified 21 qualitative studies, of which five studies ${ }^{6-10}$ met the predetermined criteria for eligibility and were included in the review. Formal meta-analysis was not possible due to the nature of the studies.

This review found that a large number of people with HIV/AIDS report experiencing depressive symptoms that are suggestive of mild-moderate depression. Studies provide statistical evidence that a greater level of spirituality in a person with HIV/AIDS is linked to fewer symptoms of depression. However, further research is required to examine the association between spirituality and clinically-diagnosed depression, as well as the impact of spirituality-focused interventions in reducing depression in people with HIV infection or AIDS.

\section{Roxanna Amuzie,}

Urology F1, North Middlesex University Hospital Trust, Sterling Way.

E-mail: Roxanna.Amuzielanmh.nhs.uk

\section{Melvyn Jones,}

(RA's supervisor), Primary Care and Population Health: UCL (Royal Free Campus), London.

This study was a dissertation undertaken as part of the UCL intercalated BSc in Primary Health Care. R Amuzie. The role of spirituality in reducing depression in men and women living with HIV/AIDS. UCL iBSc dissertation 2009.

\section{REFERENCES}

1. Vermandere M, De Lepeleire J, Smeets L, et al. Spirituality in general practice: a qualitative evidence synthesis. Br J Gen Pract 2011; DOI: 10.3399/bjgp11X606663

2. Joint United Nations Programme on HIV/AIDS. AIDS epidemic update. Geneva: UNAIDS, 2001 uww.unaids.org/en/default.asp laccessed 10 Jan 2011)

3. Ciesla J, Roberts J. Meta-analysis of the relationship between HIV infection and risk of depressive disorders. Am J Psychiatry 2001; 158(5): 725-730.

4. Leserman J. HIV disease progression: depression, stress and possible mechanisms. Biol Psychiatry 2003; 54(3): 295-306

5. Ellison C. Spiritual well-being: Conceptualization and measurement. Journal of Psychology and Theology 1983; 11: 330-340.

6. Carrico AW, Ironson G, Antoni MH, et al. A path model of the effect of spirituality on depressive symptoms and 24-h urinary-free cortisol in HIVpositive persons. J Psychosom Res 2006; 61(1): 51-58.

7. Braxton ND, Lang DD, M Sales J, et al. The role of spirituality in sustaining the psychological well-being of HIV-positive black women. Women Health 2007; 46(2-3): 1131-1129

8. Yi MS, Mrus JM, Wade TJ, et al. Religion, spirituality and depressive symptoms in patients with HIV/AIDS J Gen Intern Med 2006; 21(Suppl 5): 21-27.

9. Coleman CL, Holzemer WL. Spirituality, psychological well-being and HIV symptoms for African Americans living with HIV disease. J Assoc Nurses AIDS Care 1999; 10(1): 42-50.

10. Simoni JM, Ortiz Z. Mediational models of spirituality and depressive symptoms among HIV-Positive

Puerto Rican women. Cultur Diver Ethnic Minor

Psychol 2003; 9(1): 3-15.

DOI: 10.3399/bjgp12X625049

\section{Buprenorphine versus methadone use in opiate detoxification, are there other factors that should be considered?}

The recent research on the comparison of methadone and buprenorphine for opiate detoxification (LEEDS trial): a randomised control trial' raises an important point with regards to utilising buprenorphine and methadone in opiate detoxification.?

The authors quite rightly conclude equal clinical effectiveness between the two agents, a statement that is supported by previous studies. ${ }^{2,3}$

However, there are additional factors that should be considered when determining which one of the two would be best suited for purpose. There is evidence to support the use of buprenorphine over methadone, especially when taking into account the risk of morbidity and mortality.

Nielsen et al identified an increased risk of overdose and adverse outcomes associated with methadone when compared to burprenorphine. ${ }^{4}$

In addition to the increased number of adverse incidents, they also concluded that presenting signs (respiratory rate and Glasgow Coma Scale score) were lower in methadone-related attendances hence indicating a heightened risk of complications and death.

This was further supported by Bell and colleagues who concluded that buprenorphine was associated with lower overdose risk and lower mortality when compared to methadone. ${ }^{5}$

Although the cost of buprenorphine is higher than methadone, ${ }^{6}$ and the clinical effectiveness of both agents is on a par, it is 